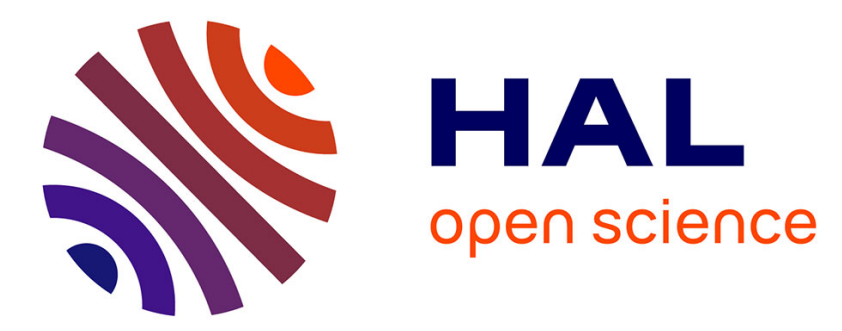

\title{
Structural characterization of krypton physisorption on (0001) graphite pre-plated with cyclohexane
}

\author{
A. Razafitianamaharavo, P. Convert, J.P. Coulomb, B. Croset, N. \\ Dupont-Pavlovsky
}

\section{- To cite this version:}

A. Razafitianamaharavo, P. Convert, J.P. Coulomb, B. Croset, N. Dupont-Pavlovsky. Structural characterization of krypton physisorption on (0001) graphite pre-plated with cyclohexane. Journal de Physique, 1990, 51 (17), pp.1961-1969. 10.1051/jphys:0199000510170196100 . jpa-00212501

\section{HAL Id: jpa-00212501 https://hal.science/jpa-00212501}

Submitted on 1 Jan 1990

HAL is a multi-disciplinary open access archive for the deposit and dissemination of scientific research documents, whether they are published or not. The documents may come from teaching and research institutions in France or abroad, or from public or private research centers.
L'archive ouverte pluridisciplinaire HAL, est destinée au dépôt et à la diffusion de documents scientifiques de niveau recherche, publiés ou non, émanant des établissements d'enseignement et de recherche français ou étrangers, des laboratoires publics ou privés. 
Classification

Physics Abstracts

$61.10-61.12-68.45$

\title{
Structural characterization of krypton physisorption on (0001) graphite pre-plated with cyclohexane
}

\author{
A. Razafitianamaharavo $\left({ }^{1}\right)$, P. Convert $\left({ }^{2}\right)$, J. P. Coulomb $\left({ }^{3}\right)$, B. Croset $\left({ }^{4}\right)$ and \\ N. Dupont-Pavlovsky ( $\left.{ }^{1}\right)$ \\ (') CNRS, Laboratoire Maurice Letort, 54600 Villers les Nancy, France \\ (2) Institut Laue Langevin, 156 Centre de Tri, 38042 Grenoble Cedex, France \\ (3) CRMC2, Département de Physique, Faculté des Sciences de Luminy, Case 901, 13288 \\ Marseille Cedex 09, France \\ ( $\left.{ }^{4}\right)$ Groupe de Physique des Solides, Paris VII, 75251 Paris Cedex 05, France
}

(Received on March 12, 1990, accepted in final form on May 18, 1990)

\begin{abstract}
Résumé. - Le film mixte formé lors de la physisorption de krypton sur une surface de graphite (0001) pré-recouverte d'une monocouche de cyclohexane a été étudié par diffraction de neutrons et de rayons $\mathrm{X}$. L'organisation de la couche mixte prévue à partir des résultats obtenus par volumétrie d'adsorption sur une surface très uniforme (graphite exfolié) est dans son ensemble conservée sur les échantillons de graphite exfolié recomprimé (Papyex) utilisés pour les expériences de diffraction, malgré les difficultés d'atteinte de l'équilibre d'adsorption liées à la densité du Papyex. L'adsorption de krypton à $77 \mathrm{~K}$ provoque la compression de la couche de cyclohexane pré-adsorbé jusqu'à son état le plus dense, puis son déplacement partiel et la formation de cristallites tridimensionnels. La fraction de cyclohexane restant à l'état adsorbé est impliquée dans une solution bidimensionnelle avec le krypton, de structure commensurable $\sqrt{3} \times \sqrt{3}$. Au-delà de la première couche, le krypton s'adsorbe sur lui-même.
\end{abstract}

\begin{abstract}
The structural characterization of the composite film formed by physisorption of krypton on (0001) graphite pre-plated with a monolayer of cyclohexane has been performed by neutron and X-ray diffraction. The organization of the composite film predicted by means of volumetric measurements on a very uniform surface (exfoliated graphite) is mostly preserved on compressed exfoliated graphite (Papyex) used for diffraction experiments in spite of enhanced difficulties in reaching the adsorption equilibrium, resulting from the Papyex density. Krypton adsorption at $77 \mathrm{~K}$ results in the compression of the pre-adsorbed cyclohexane layer to its densest state, followed by its partial displacement and the formation of three-dimensional crystallites. The fraction of cyclohexane remaining in the adsorbed state is involved in a two-dimensional solution with krypton, of $\sqrt{3} \times \sqrt{3}$ commensurate structure. Beyond the first layer, krypton adsorbs on itself.
\end{abstract}

\section{Introduction.}

The study of two-component physisorbed films is one of the natural extensions of the analysis of pure two-dimensional (2D) film properties on uniform surfaces. Dimensionality reduction and substrate influence may lead to an original behaviour of these $2 \mathrm{D}$ composite films, 
compared to that of bulk binary alloys. Within the last few years, structural characterizations of these films have been carried out and in some cases 2D solid solutions have been evidenced [1-7]. When the respective temperatures of condensation of the two adsorbates are very different, classical volumetric measurements can be applied to the thermodynamic characterization of the composite film by means of the preadsorbed layer technique, which was introduced by Halsey and Singleton [8], and extended later on [9-13]. The most condensable adsorbate is introduced first at relatively high temperature, in order to control the adsorption equilibrium ; the sample is then cooled down to the temperature of the second component adsorption. At the temperature of the composite film study, the partial pressure of the most condensable adsorbate can be neglected in the gas-phase, and information obtained from the comparison of the less condensable component properties on bare and pre-plated graphite. This technique was used for the last two systems studied, $\mathrm{Kr}_{-} \mathrm{SF}_{6} /$ graphite [12] and $\mathrm{Kr}-\mathrm{C}_{6} \mathrm{H}_{12}$ /graphite [13]. In both cases, krypton adsorption was shown to result in the displacement of the pre-adsorbed film. A recent theoretical work has clarified these phenomena [14]. We present here a structural investigation of the $\mathrm{Kr}-\mathrm{C}_{6} \mathrm{H}_{12}$ /graphite system by neutron and $\mathrm{X}$-ray diffraction. Our results point out clear evidence of the $\mathrm{C}_{6} \mathrm{H}_{12}$ layer displacement by krypton adsorption and simultaneous formation of bulk (3D) cyclohexane crystallites. Before a detailed description of the experimental procedure and diffraction results, some information on the adsorptive properties of pure krypton and cyclohexane and on the results of the thermodynamic characterization of the $\mathrm{Kr}-\mathrm{C}_{6} \mathrm{H}_{12}$ /graphite film is presented.

\section{Adsorptive properties of pure krypton and cyclohexane on graphite.}

1.1 KRYPTON. - Thermodynamical and structural properties of pure krypton adsorbed on (0001) graphite have been extensively studied; (see, for instance, [15-21]). Discrete layers may form on the substrate, whatever the film thickness.

The krypton monolayer phase diagram is characterized by a two-dimensional (2D) critical temperature estimated to be $86 \mathrm{~K}$ [16-19] and by a very narrow [16] or even inexistent [18] temperature range for the coexistence of $2 \mathrm{D}$ gas and $2 \mathrm{D}$ liquid. At the temperature of the composite film study $(77 \mathrm{~K})$, krypton condensation leads to a $2 \mathrm{D}$ commensurate solid with a $\sqrt{3} \times \sqrt{3} \mathrm{R} 30^{\circ}$ structure, whose X-ray diffraction profile exhibits a (10) Bragg peak located at $Q=1.703 \AA^{-1}$. Near the monolayer completion, this solid changes into an incommensurate hexagonal structure of higher density [19-21].

1.2 CyCloheXANe. - Cyclohexane adsorption has been investigated by isotherm measurements [22-23], and more recently diffraction techniques [24-25]. Isotherms measured between 203 and $293 \mathrm{~K}$ exhibit two steps, corresponding to the adsorption of two monolayers before reaching the saturating vapour pressure. From the temperature dependence of the second step pressure, the second layer was estimated to appear at $145 \mathrm{~K}$. Below $145 \mathrm{~K}$, only one monolayer is adsorbed before $3 \mathrm{D}$ condensation.

Depending on coverage, three solids may be observed at $77 \mathrm{~K}$, whose structures are in order of increasing density, hexagonal commensurate $\sqrt{7} \times \sqrt{7}(a=6.51 \AA)$, hexagonal incommensurate $(a=6.35 \AA)$, and centered rectangular incommensurate $(a=5.63 \AA$, $b=6.06 \AA, \gamma=117.65^{\circ}$ ).

\section{Thermodynamic characterization of the composite film.}

The thermodynamic characterization of krypton adsorption on (0001) graphite pre-plated with cyclohexane was performed by means of volumetric measurements, according to the pre- 
adsorbed layer technique mentioned in the introduction [13, 25]. Cyclohexane was adsorbed at $233 \mathrm{~K}$, in order to enable the equilibrium pressure control. The sample was then cooled down to the temperature of krypton introduction, and isotherm measurements performed at $77 \mathrm{~K}$. At this temperature, the partial pressure of $\mathrm{C}_{6} \mathrm{H}_{12}$ in the gas phase is very low (about $10^{-15}$ torr) and can be neglected. When the graphite surface is pre-covered with a monolayer of cyclohexane, it was shown that krypton adsorption becomes important under pressures definitely higher than on bare graphite. From the comparison of krypton adsorption isotherms on bare graphite and on cyclohexane pre-plated graphite, krypton adsorption was suggested to result in a partial displacement of the cyclohexane film, followed by krypton condensation on itself. Displaced cyclohexane was assumed to form 3D crystallites. The fraction of $2 \mathrm{D}$ cyclohexane remaining on the surface was suggested to be involved in a $2 \mathrm{D}$ krypton-cyclohexane solution.

\section{Experimental details.}

3.1 APPARATUS. - The structural characterization was performed by neutron and X-ray diffraction. The neutron diffraction experiments were carried out at the Laue Langevin Institute on the D $1 \mathrm{~B}$ spectrometer. The X-ray diffraction experiments were carried out at the G.P.S. laboratory. Both diffraction experiments have been described elsewhere [25-26].

3.2 ADSORBATES. - Krypton of $99.94 \%$ purity was supplied by "l'Air liquide ". Cyclohexane was a Merck product of $99.7 \%$ purity. The adsorbates were purified before each experiment by pumping on the condensed phase inside the introduction system at $77 \mathrm{~K}$ for krypton and $193 \mathrm{~K}$ (dry ice temperature) for cyclohexane.

3.3 SUBSTRATES. - Whereas the thermodynamic characterization was performed on exfoliated graphite, which exhibits a very uniform surface, diffraction experiments were performed on Papyex, supplied by the firm "Le Carbone Lorraine ». It is a compressed exfoliated graphite with a preferential orientation of the six-fold axis. Two samples were used. One was compressed to $1.1 \mathrm{~g} . \mathrm{cm}^{-3}$, having a specific surface area estimated to be $20 \mathrm{~m}^{2} . \mathrm{g}^{-1}$ and a mosaic spread of $38^{\circ}$ (full width at half maximum). The other was compressed to $0.1 \mathrm{~g} . \mathrm{cm}^{-3}$, with a $40 \mathrm{~m}^{2} \cdot \mathrm{g}^{-1}$ specific surface area and mosaic spread of $74^{\circ}$ [27].

Compression of exfoliated graphite results in an increase of the surface area per volume unit and a preferential orientation of the six fold axis, which makes it more suitable than uncompressed exfoliated graphite for diffraction experiments, but it also results in a decrease of the surface uniformity [27-28]. The main modifications in the composite film formation, compared to that observed on exfoliated graphite, are then extra capillary condensation and enhanced difficulty in reaching the equilibrium after krypton introduction. Krypton adsorption isotherms at $77 \mathrm{~K}$ on cyclohexane pre-plated graphite presented in figure 1 are measured on the same surface area for each of the three substrates considered, and under the same conditions of film formation. Their main difference lies in the height of the first step, which is lower on Papyex, and decreases with increasing density of the sample. But on the whole, the properties of the (cyclohexane-krypton) films formed on exfoliated graphite and on Papyex respectively appear close enough to enable the comparison of results obtained on both kinds of samples.

For X-ray as well as for neutron studies, the sample was a stack of Papyex disks arranged parallel to the scattering plane. Details of the experimental procedure are given elsewhere $[26,27,29,30]$. 


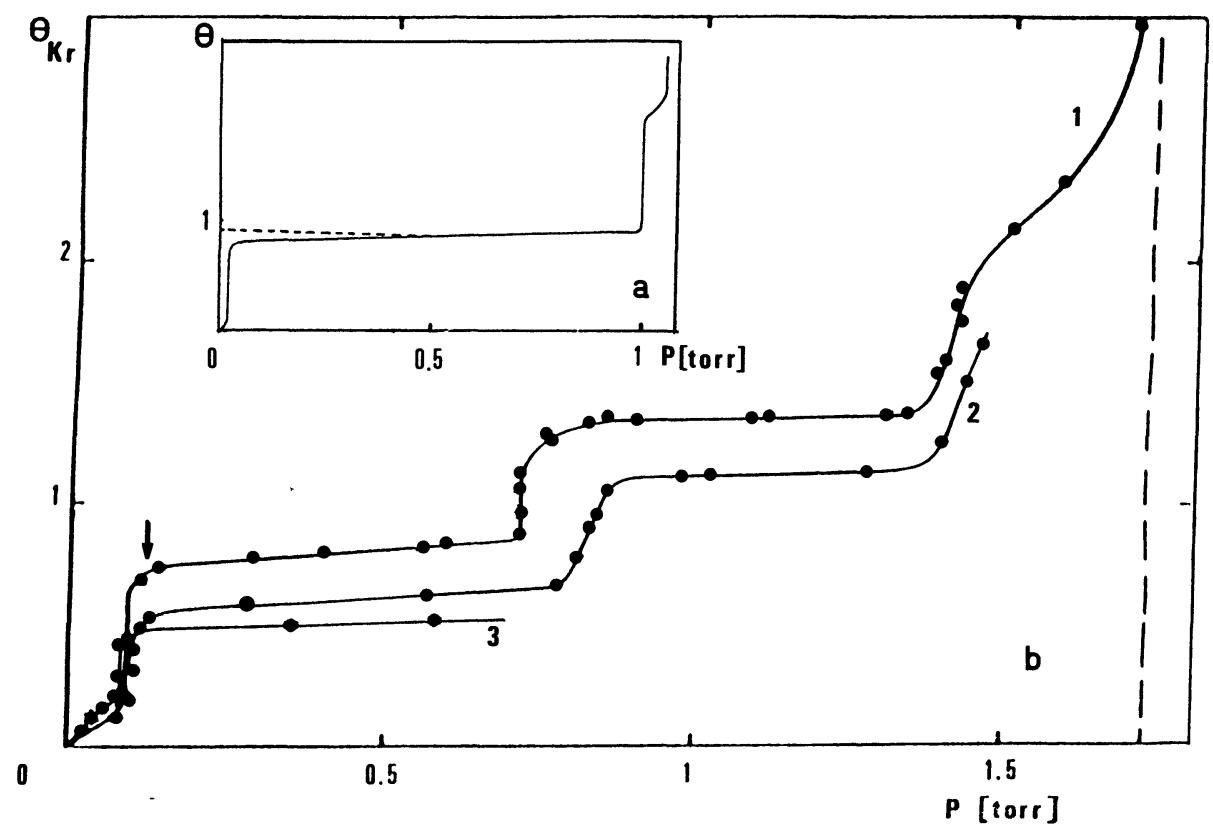

Fig. 1. - Adsorption isotherms of cyclohexane on graphite, and krypton on cyclohexane-pre-plated graphite. a) Adsorption of cyclohexane on graphite at $233 \mathrm{~K}$. Schematic drawing presented in order to define the amount of cyclohexane corresponding to a monolayer. $\theta=$ cyclohexane fractional coverage. This definition of the monolayer was adopted in the course of volumetric measurements, before the structural investigation. It does not correspond to the densest state of the solid monolayer, as was shown afterwards, by the diffraction experiments [24]. b) Adsorption of krypton at $77 \mathrm{~K}$ on graphite pre-plated with a monolayer of cyclohexane. Dependence of the isotherm shape on the substrate : 1) adsorption on exfoliated graphite ; 2) adsorption on 0.1 density Papyex ; 3) adsorption on 1.1 density Papyex ; $P$ : pressure $; \theta_{\mathrm{kr}}$ : krypton fractional coverage $; \theta=1$ corresponds to a monolayer on bare graphite. In the following figures, describing the composite film, the krypton monolayer will be defined as the top of the first step of the composite film isotherm for each kind of sample.

3.4 ADSORPTION PROCEDURE. - The experimental conditions for the composite film formation are exactly the same as those of the thermodynamic characterization [13]. A cyclohexane amount corresponding to the adsorption of a monolayer, as defined in figure 1a, is introduced at $233 \mathrm{~K}$. The sample is then slowly cooled ( 0.5 degree per minute), in order to avoid any distillation on the cell walls, down to $150 \mathrm{~K}$, which is the temperature of krypton introduction. Spectra are measured at $77 \mathrm{~K}$, but the sample is annealed at $150 \mathrm{~K}$ for each krypton introduction, in order to increase the mobility of the adsorbates during the composite film organization.

The krypton coverage which is assumed to correspond to a monolayer in the composite film is defined as the top of the first step of the composite film isotherm for each kind of sample.

\section{Results.}

Neutron and X-ray diffraction are two complementary techniques for the study of the (krypton-cyclohexane) films adsorbed on graphite, since neutrons are strongly scattered by cyclohexane at least in its deuterated form $\mathrm{C}_{6} \mathrm{D}_{12}$, and weakly by krypton, whereas for $\mathrm{X}$ rays, exactly the opposite situation prevails. The $\mathrm{C}_{6} \mathrm{D}_{12}$ diffraction patterns, and their 
modification after krypton adsorption were then examined by neutron diffraction. Krypton patterns were obtained by X-ray diffraction.

4.1 NeUtron Diffraction EXPERIMENTS $-\mathrm{C}_{6} \mathrm{D}_{12}$ PROFIles. - The spectra in figure 2 are presented in order to show the reversibility of the composite film formation. The evolution of a monolayer $\mathrm{C}_{6} \mathrm{D}_{12}$ profile in the presence of a monolayer krypton amount is examined as a function of temperature, which is varied in the course of time. Each line represents a different spectrum. In the wave vector range considered, the pure $C_{6} D_{12}$ profile is characterized by one peak, observed at $150 \mathrm{~K}$, no krypton adsorption occurring at this temperature. If the system is cooled down to $77 \mathrm{~K}$, krypton adsorbs, and the spectrum is strongly modified, with two new peaks arising. The pure $\mathrm{C}_{6} \mathrm{D}_{12}$ profile is restored by heating again the sample up to $150 \mathrm{~K}$ and desorbing krypton.

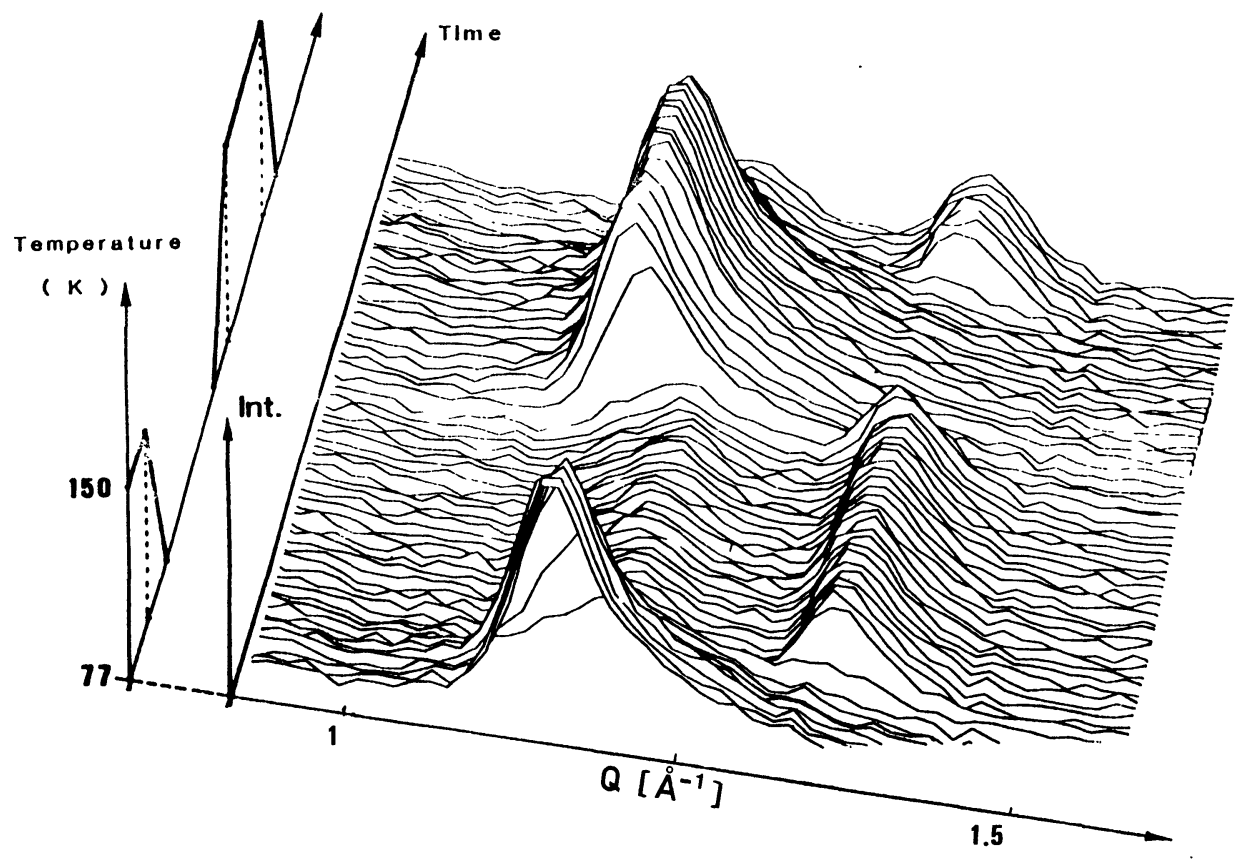

Fig. 2. - Neutron diffraction profiles of a cyclohexane monolayer adsorbed on 0.1 density Papyex in the presence of krypton. Dependence of the profile shape on the temperature, i.e. on krypton adsorption. Int.: intensity, in arbitrary units; $Q$ : wave vector. Each line represents a different spectrum. The time between two spectra is $30 \mathrm{~min}$.

Spectra measured at $77 \mathrm{~K}$ for a larger wave vector range than in figure 2, and for different krypton coverages are shown in figure 3 , as well as pure $\mathrm{C}_{6} \mathrm{D}_{12}$ profiles for the hexagonal incommensurate and centered rectangular structures (the profile of the centered rectangular structure is obtained by subtracting the 3D contribution to the spectrum obtained with a 1.3 layer film adsorbed at $77 \mathrm{~K}$ ). A spectrum obtained when introducing a $\mathrm{C}_{6} \mathrm{D}_{12}$ amount equivalent to fifteen layers in contact with the sample is representative of the 3D structure at this temperature (Fig. 3e). Before krypton adsorption, the $\mathrm{C}_{6} \mathrm{D}_{12}$ profile is that of figure $3 \mathrm{a}$. A significant modification of the $\mathrm{C}_{6} \mathrm{D}_{12}$ structure occurs even when a 0.5 krypton monolayer is adsorbed (Fig. 3c). Numerous new Bragg peaks appear, whose relative intensity modifications with krypton coverage depend on their positions : 


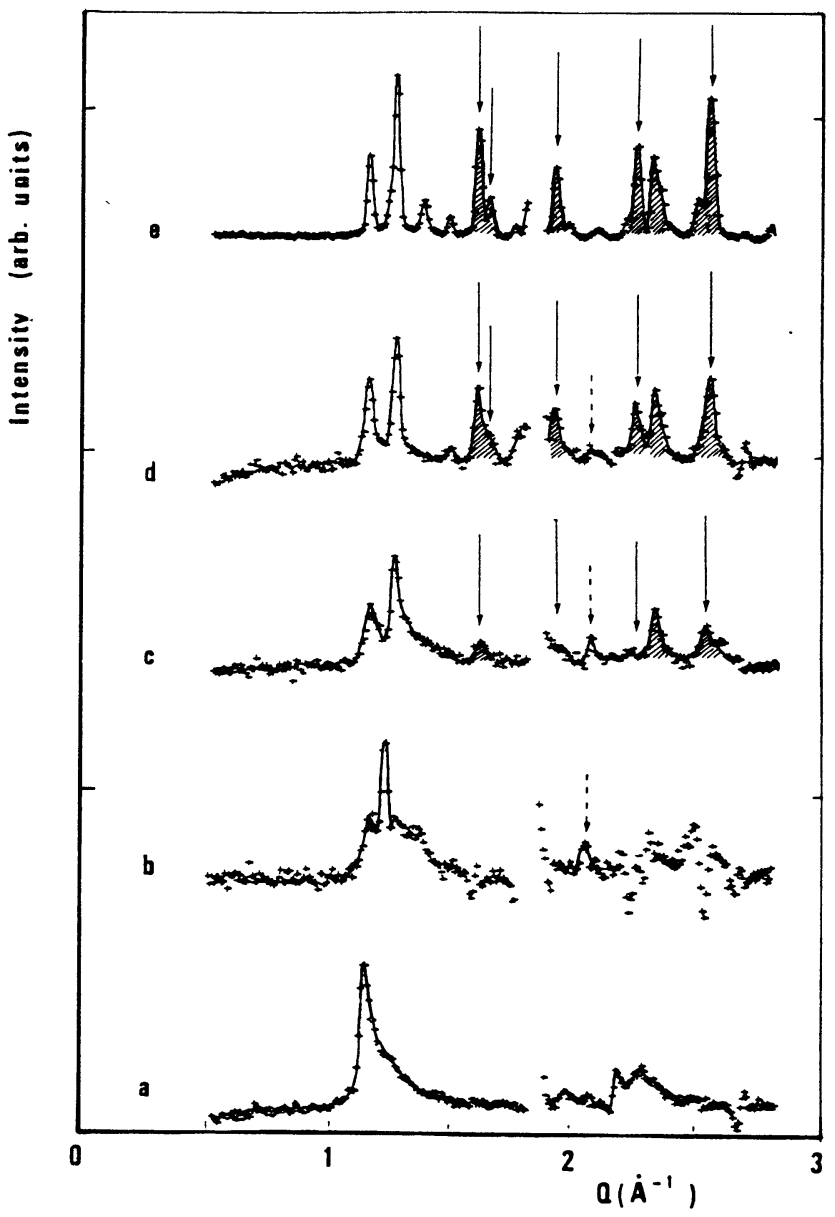

Fig. 3. - Neutron diffraction profiles of films adsorbed on 0.1 density Papyex at $77 \mathrm{~K}:$ a) pure $\mathrm{C}_{6} \mathrm{H}_{12}$, hexagonal incommensurate structure; b) pure $\mathrm{C}_{6} \mathrm{H}_{12}$, centered rectangular structure; c) composite film, 0.5 krypton monolayer on a $\mathrm{C}_{6} \mathrm{H}_{12}$ layer; d) composite film, 1.2 krypton monolayer on a $\mathrm{C}_{6} \mathrm{H}_{12}$ layer; e) pure $\mathrm{C}_{6} \mathrm{H}_{12}$, fifteen layers, this profile is representative of the $3 \mathrm{D} \mathrm{C}_{6} \mathrm{H}_{12}$ structure; $Q$ : wave vector. Bragg peaks, which are hatched and marked by an arrow in solid line, increase in intensity with increasing krypton amount in the composite film (Fig. $\mathrm{c}$ and d). They all appear in the pure $\mathrm{C}_{6} \mathrm{H}_{12}$ 3D profile (Fig. e). The Bragg peak, which is marked by an arrow in dotted line, decreases in intensity with increasing krypton amount in the composite film (Fig.c and d). This peak also appears in the pure $\mathrm{C}_{6} \mathrm{H}_{12}$ profile corresponding to the centered rectangular structure (Fig. b).

- some of them, marked by arrows in figures $3 \mathrm{c}$ and $3 \mathrm{~d}$, clearly increase with increasing krypton coverage. They are located at $1.62,1.66,1.93,2.27 \AA^{-1}$. They all belong also to the $3 \mathrm{D} \mathrm{C}_{6} \mathrm{D}_{12}$ profile shown in figure 3e. Moreover, with increasing krypton coverage, the spectrum of $\mathrm{C}_{6} \mathrm{D}_{12}$ involved in the composite film becomes closer and closer to that of pure $3 \mathrm{D} \mathrm{C}_{6} \mathrm{D}_{12}$ in accordance with the assumption of $3 \mathrm{D} \mathrm{C}_{6} \mathrm{D}_{12}$ formation produced by krypton adsorption ;

- a Bragg peak marked by a dotted arrow, and located at $2.1 \AA^{-1}$, can be distinguished in the two composite film spectra. Its intensity decreases with increasing krypton coverage. This Bragg peak appears also in the profile of pure $\mathrm{C}_{6} \mathrm{D}_{12}$ centered rectangular structure, 
corresponding to the densest state of the monomolecular $C_{6} D_{12}$ film (Fig. $3 b$ ); it seems then that krypton adsorption results first in a compression of the $C_{6} D_{12}$ film, which is displaced in a second step and forms $3 \mathrm{D}$ crystallites;

- the remaining Bragg peaks of the composite film spectra, located at $1.17,1.26$ and $2.36 \AA^{-1}$, may belong to spectra of both $3 \mathrm{D} \mathrm{C}_{6} \mathrm{D}_{12}$ and $2 \mathrm{D} \mathrm{C}_{6} \mathrm{D}_{12}$ with centered rectangular structure. Their relative intensity does not change significantly with krypton coverage. This behaviour can be assigned to a balance between the displacement of $2 \mathrm{D} \mathrm{C}_{6} \mathrm{D}_{12}$ with rectangular structure and the growth of $3 \mathrm{D} \mathrm{C}_{6} \mathrm{D}_{12}$ crystallites with an increasing amount of adsorbed krypton.

The displacement of pre-adsorbed cyclohexane by krypton adsorption, and the formation of $3 \mathrm{D}$ cyclohexane crystallites, which were assumed after the volumetric measurements, are then clearly demonstrated. Moreover, the compression of the 2D cyclohexane film from a hexagonal incommensurate to a centered rectangular structure, occurring in the initial stages of krypton adsorption, is also evidenced. It should be noticed that the $2 \mathrm{D}$ compressed $\mathrm{C}_{6} \mathrm{D}_{12}$ structure can still be distinguished after admission of 1.2 krypton monolayer. This observation is quite unexpected, since a 2D cyclohexane displacement, according to a first order transition process should have resulted in a complete removing of the preadsorbed gas after admission of more than one krypton monolayer. But, as has already been emphazised above, it is much more difficult and time consuming to reach the equilibrium state on Papyex, used for diffraction experiments, than on exfoliated graphite, used for the volumetric characterization. 2D cyclohexane with a dense structure which remains on the surface could be a nonequilibrium manifestation.

4.2 X-RAY DIFFRACTION EXPERIMENTS - KRYPTON PROFILES. - X-ray diffraction spectra shown in figure 4 are mostly representative of krypton involved in the composite film. The unusual shape of these $2 \mathrm{D}$ peaks is mainly due to the vicinity of the (002) graphite Bragg peak. More surprising is the shape of the low- $Q$ side of the krypton Bragg peak in figure 4c. We have no clear explanation for it, but it should be noticed that $3 \mathrm{D}$ cyclohexane exhibits two Bragg peaks located at $Q=1.6$ and $Q=1.68 \AA^{-1}$, respectively, which could alter the shape of the krypton Bragg peak.

The Bragg peaks observed for krypton coverages below two layers are located at $Q=1.70 \AA^{-1}$. This wave-vector value is representative of a $\sqrt{3} \times \sqrt{3}$ structure, whose stabilization during the cyclohexane film displacement, which was predicted by the volumetric characterization, is then confirmed. This stabilization is observed at an equilibrium pressure much higher than that of the pure film commensurate-incommensurate transition at the same temperature, near the monolayer completion. This is a serious indication in favour of the existence of a 2D binary solution, as has already been observed in the case of other binary mixtures adsorbed on graphite. Whenever a commensurate structure exists in the first layer, it is stabilized over a larger range of temperatures and pressures by dissolution of larger molecules [3, 6, 11, 32]. When the coadsorbed gas is insoluble in the krypton film, the commensurate-incommensurate $2 \mathrm{D}$ solid transition is observed, as, for instance, for the $D_{2} / \mathrm{Kr}$ system [33]. $D_{2}$ was then used as a source of $2 \mathrm{D}$ pressure to push a commensurate krypton layer to a denser incommensurate structure. When two layers of krypton are adsorbed on cyclohexane pre-plated graphite (Fig. 4c), the Bragg peak shifts towards larger wave vectors, and its position is that of the usual pure krypton incommensurate structure, in accordance with the assumption of krypton adsorbing on itself after cyclohexane displacement. 


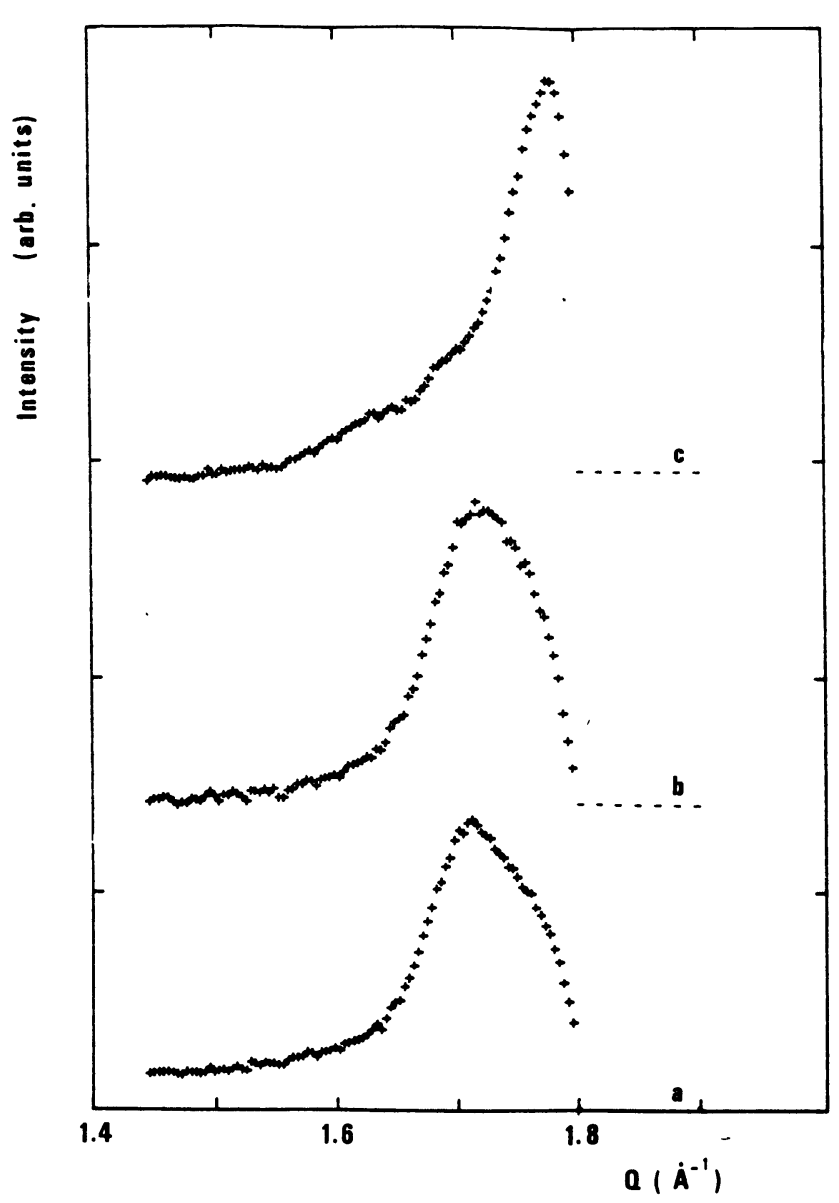

Fig. 4. - X-ray diffraction profiles of composite films adsorbed on 1.1 density Papyex at $77 \mathrm{~K}$. Adsorption on one $\mathrm{C}_{6} \mathrm{H}_{12}$ monolayer of a) 0.8 krypton monolayer; b) 1 krypton monolayer; c) 2 krypton monolayers. Dashed lines on the abscissa correspond to the position of the most intense substrate peaks.

\section{Conclusion.}

In conclusion, the structural characterization of the composite film formed by the adsorption of krypton on cyclohexane pre-plated graphite corroborates the assumptions proposed by A. Razafitianamaharavo et al. [13] after their volumetric studies, and gives additional information. Krypton adsorption at $77 \mathrm{~K}$ results in the compression of a pre-adsorbed cyclohexane layer to its densest state, followed by its partial displacement and the formation of $3 \mathrm{D}$ crystallites. The fraction of cyclohexane remaining in the adsorbed film is involved in a 2D (krypton-cyclohexane) solution with a commensurate $\sqrt{3} \times \sqrt{3}$ structure. For coverages higher than one monolayer, krypton is adsorbed on itself with an incommensurate hexagonal structure.

\section{Acknowledgments.}

The authors are grateful to professors X. Duval and C. Marti, and to G. Pepe, A. Thomy and T. Ceva for helpful discussions. 


\section{References}

[1] Bohr J., Nielsen M., Als-Nielsen J., KJaer K., McTague J., Surf. Sci. 125 (1983) 181.

[2] Allen M. P., Hovenden C. B., Humes R. P., Methas K., Thomas R. K., White M. A., Faraday Discuss. Chem. Soc. 80 (1985) 171.

[3] Stephens P. W., Goldman A. I., Heiney P. A., Bancel P. A., Phys. Rev. B 33 (1986) 655.

[4] You H., Fain S. C., Satija S., Passel L., Phys. Rev. Lett. 56 (1986) 244.

[5] You H., Fain S. C., Phys. Rev. B 34 (1986) 2841.

[6] Ceva T., Goldmann M., Marti C., J. Phys. France 47 (1986) 1527.

[7] Satija S. K., Sutton M., Birgeneau R. J., Hong H., Passel L., Wicksted J. P., Phys. Rev. B 35 (1987) 2064.

[8] Singleton J. H., Halsey J. G. Jr., J. Phys. Chem. 58 (1954) 330.

[9] Steele W. A., Aston J. G., J. Chem. Phys. 23 (1955) 1547.

[10] Prenslow C. F., Beard H. R., Brundage B. S., J. Phys. Chem. 75 (1969) 968.

[11] Régnier J., Bockel C., Dupont-Pavlovsky N., Surf. Sci. 112 (1981) L770.

[12] Bouchdoug M., Menaucourt J., Thomy A., J. Phys. France 47 (1986) 1797.

[13] Razafitianamaharavo A., Dupont-Pavlovsky N., Thomy A., J. Phys. France 51 (1990) 91.

[14] Mutaftschiev B., Phys. Rev. B 40 (1989) 779.

[15] ThомY A. and Duval X., J. Chim. Phys. 67 (1970) 1101.

[16] Larher Y., J. Chem. Soc. Faraday Trans. 170 (1974) 320.

[17] Chinn M. D. and Fain S. C. Jr., Phys. Rev. Lett. 39 (1977) 146.

[18] Butler D. M., Litzinger J. A., Stewart C. A. and Griffiths B. B., Phys. Rev. Lett. 42 (1979) 1289.

[19] Thomy A., Duval X. and Régnier J., Surf. Sci. Rep. 1 (1981) 1.

[20] Nielsen M., Bohr J., KJAer K. and Als-Nielsen J., Nucl. Instr. Methods 208 (1988) 549-554.

[21] Stephens P. W., Heiney P. M., Birgeneau R. J., Horn P. M., Moncton D. E. and Brown G. S., Phys. Rev. B 29 (1984) 3512.

[22] Khatir Y., Coulon M. and Bonnetain L., J. Chim. Phys. 75 (1978) 796.

[23] Delachaume J. C., Thesis Grenoble (1985).

[24] Razafitianamaharavo A., Convert P., Coulomb J. P., Croset B. and Dupont-Pavlovsky N., J. Phys. France 50 (1989) 3133.

[25] Razafitianamaharavo A., Thesis Nancy (1989).

[26] Marti C., Ceva T., Croset B., De Beauvais C. and Thomy A., J. Phys. France 47 (1986) 1517.

[27] Coulomb J. P., Thesis Marseille (1981).

[28] Bockel C., Coulomb J. P. and Dupont-Pavlovsky N., Surf. Sci. 116 (1982) 369.

[29] Suzanne J., Coulomb J. P., Bienfait M., Matecki M., Thomy A., Croset B. and Marti C., Phys. Rev. Lett. 41 (1978) 760.

[30] Coulomb J. P., Suzanne J., Bienfait M., Matecki M., Thomy A., Croset B. and Marti C., J. Phys. France 41 (1980) 1155.

[31] Kahn R., Fourme R., André D. and Renaud M., C.R. Acad. Sci. 271B (1970) 1078 ; Kahn R., Fourme R., André D. and Renaud M., Acta Crystallogr. B 29 (1973) 131.

[32] Migone A. D., Li Z. R., Chan M. H. W. and Giri M. R., Phys. Rev. B 28 (1983) 6525.

[33] Nielsen M., Als-Nielsen J., Bohr J., McTague J. P., Phys. Rev. Lett. 47 (1981) 582. 